\title{
A ANÁLISE DA DEFORMAÇÃO FINITA EM ROCHAS METASSEDIMENTARES DA REGIÃO DA SERRA DA MATRICULADA, MUNICÍPIO DE DATAS (MG), SERRA DO ESPINHAÇO MERIDIONAL
}

\author{
Juni Silveira Cordeiro ${ }^{1}$, Luiz Guilherme Knauer ${ }^{2}$, Ricardo Diniz da Costa ${ }^{3}$, \\ Danielle Piuzana $^{4} \&$ Joana Tiago Reis Magalhães ${ }^{5}$
}

\section{Resumo}

\begin{abstract}
A região de Datas (MG), uma das mais intensamente deformadas da Folha Diamantina, é marcada por um importante sistema de frentes de cavalgamento que envolvem lascas tectônicas de unidades tanto do Supergrupo Espinhaço como do Grupo Costa Sena e do Complexo de Gouveia. Foram analisadas 25 amostras de quartzitos (através de seções delgadas paralelas à lineação mineral de estiramento - plano XZ e nos cortes a ela perpendiculares - plano YZ) pertencentes às formações São João da Chapada ("Nível C") e Sopa-Brumadinho (Membro Caldeirões) através das técnicas de quantificação da deformação $\mathrm{R} / \varphi$ ' e Fry. A maioria das seções analisadas indica uma maior absorção da deformação pelos grãos, com valores de $R s$ variando, no plano $\mathrm{XZ}$, entre 1,78 e 4,71 quando estimados por $\mathrm{R} / \varphi^{\prime}$. Os valores da razão inicial $\left(\mathrm{R}_{0}\right)$ obtidos também pela aplicação de $\mathrm{R}_{\mathrm{f}} / \varphi^{\prime}$ mostram-se relativamente altos nos planos XZ, variando entre 1,36 e 2,13. Já o Parâmetro de Flinn, considerando os dados obtidos através da aplicação de ambas as técnicas, indica que praticamente todas as amostras consideradas representam elipsóides oblatos. As estimativas das mudanças sofridas em cada eixo cinemático (considerando, novamente, os dados alcançados pelo método $\mathrm{R}_{\mathrm{f}} / \varphi^{\prime}$ ) mostram variações entre $+17 \%$ e $+82 \%$ no eixo $\mathrm{X}$, entre $-04 \%$ e $40 \%$ no eixo $\mathrm{Y}$, e entre $-53 \%$ $\mathrm{e}-22 \%$ no eixo $Z$.
\end{abstract}

Palavras-chave: Serra da Matriculada, Supergrupo Espinhaço, quantificação da deformação, método $R_{f} / \varphi^{\prime}$

\section{INTRODUÇÃO E LOCALIZAÇÃO GEOGRÁFICA}

Entendendo-se deformação ou strain como o conjunto nas modificações na posição, forma e/ou volume de um corpo rochoso como resposta a aplicação de um campo de esforços, fica evidente a importância de sua quantificação. Houve, a partir do final da década de 90, um impulso global quando foram desenvolvidos programas computacionais de livre acesso que tornaram mais fáceis e práticas o entendimento da trama mineral e consequentemente das análises da deformação (Rodrigues \& Faleiros 2007). Entretanto, as técnicas de quantificação da deformação têm sido aplicadas de maneira limitada no país, o que pode ser exemplificado pela própria porção meridional da Serra do Espinhaço, onde apenas três afloramentos isolados de metaconglomerados foram submetidos a análises de caráter inicial (Kalt 1991; Silva \& Uhlein 1985) e outras quatro dezenas de afloramentos quartzíticos foram examinados por Knauer (1999).

O objetivo deste trabalho é apresentar os resultados obtidos com a quantificação da deformação, através da aplicação dos métodos $\mathrm{R}_{\mathrm{f}} / \varphi$ ' (e.g. Ramsay 1967, Ramsay \& Huber 1983) e Fry (1979), em amostras de rochas quartzíticas coletadas na região da Serra da Matriculada, a norte do município de Datas, Serra do Espinhaço Meridional.

A Serra do Espinhaço é uma cordilheira com mais de $1200 \mathrm{~km}$ de extensão na direção aproximadamente norte-sul, abrangendo áreas dos estados de Minas Gerais e Bahia. Sua porção meridional estende-se por cerca de $300 \mathrm{~km}$, estando localizada integralmente em território mineiro e constituindo um dos principais acidentes geográficos deste estado.

O município de Datas está inserido na porção central da Serra do Espinhaço (Figura 1), distante cerca de $260 \mathrm{~km}$ de Belo Horizonte. $\mathrm{O}$ acesso à área pode ser realizado a partir de Belo Horizonte pela rodovia BR040 em direção a Sete Lagoas, a partir da qual se segue pela BR-135 rumo a Curvelo, BR-259 passando por Gouveia e a seguir MG-02 que dá acesso às localidades de Datas e Serro.

\section{CONTEXTO GEOLÓGICO REGIONAL}

O modelo estratigráfico adotado neste trabalho (Figura 2) é aquele sugerido por Knauer (1990, 1999), baseado nos trabalhos de Pflug $(1965,1968)$, e nas modificações propostas por Schöll \& Fogaça (1979, 1981), Fogaça et al. (1984), Dossin et al. (1985) e Almeida-Abreu (1993).

$\mathrm{O}$ arranjo proposto reconhece como unidades principais da região investigada o Complexo de Gouveia, o Grupo Costa Sena, o Supergrupo Espinhaço e a Suíte Metaígnea Pedro Lessa (Figura 3).

O Complexo de Gouveia é representado por granitos e migmatitos, contendo pequenos corpos de anfibolito associados (Schöll \& Fogaça 1981). Datação geocronológica do granito de Gouveia pelo método $\mathrm{U} / \mathrm{Pb}$ em zircões forneceu idades de cristalização de $2839 \pm 14 \mathrm{Ma}$, com regressão linear em $1844 \pm 15 \mathrm{Ma}$ (Machado et al. 1989).

Definido por Fogaça et al. (1984), o Grupo Costa

1 - Mestranda em Geologia Regional CGE/NGU/CPMTC-IGC-UFMG (junicordeiro@gmail.com);

2 - CGE/NGU/CPMTC-IGC-UFMG (gknauer@gmail.com) ; 3 - NGU/CPMTC-IGC-UFMG (biduufmg@gmail.com); 4 - FACESA-UFVJM (dpiuzana@yahoo.com.br) ; 5 - Graduando em Geologia - IGC-UFMG 


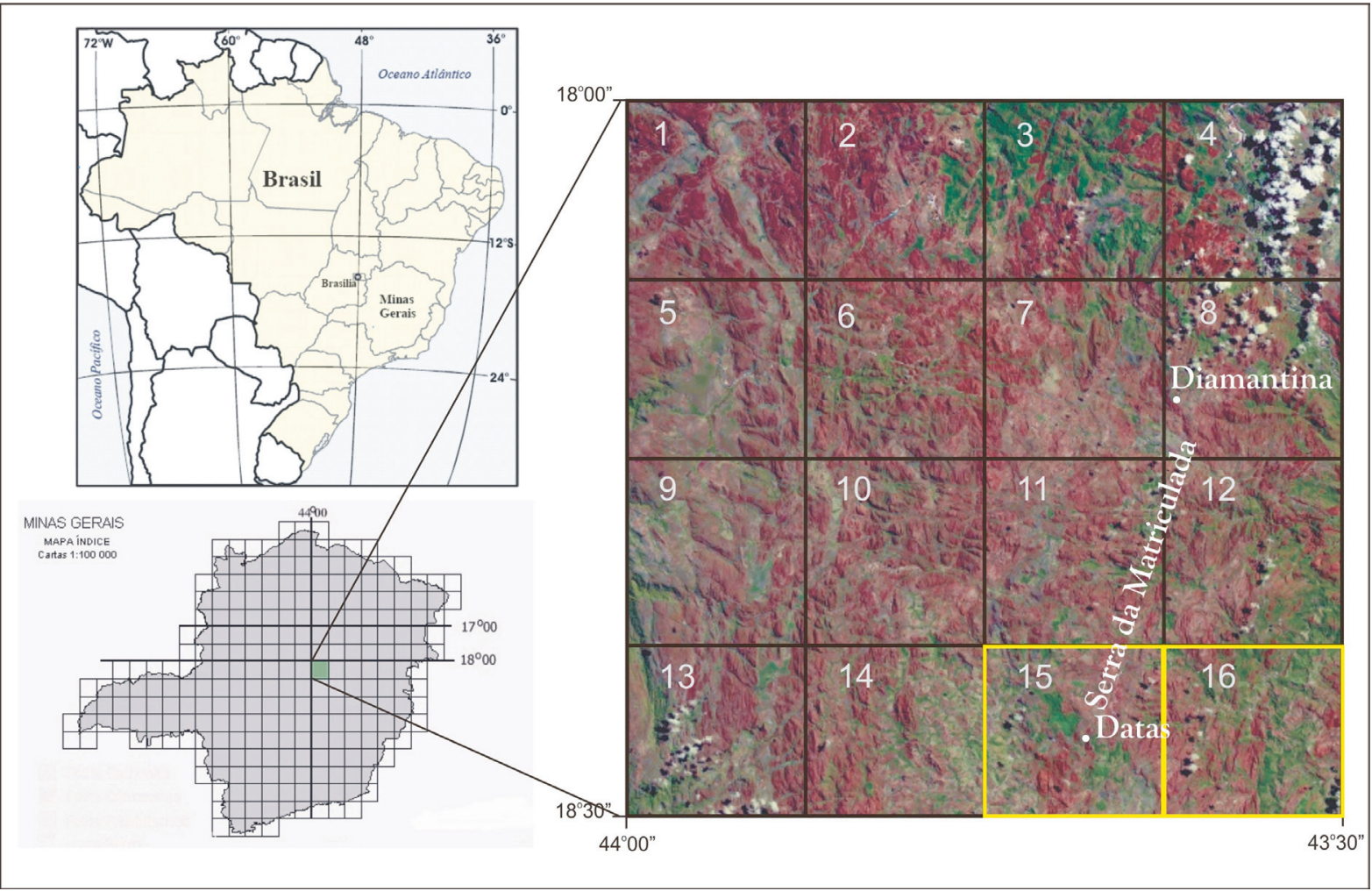

Figura 1: Mapa de localização dos municipios de Diamantina Datas, com enfoque para seu posicionamento no âmbito da Folha Diamantina (1: 100.000) e suas respectivas quadrículas na escala 1: 25.000, com destaque para as quadriculas de Gouveia e Vau, abrangidas por esse trabalho: 1- Santa Rita; 2- Campo Sampaio; 3São João da Chapada; 4- Mendanha; 5- Batatal; 6- Morro do Capim; 7- Sopa; 8- Diamantina; 9- Conselheiro Mata; 10-Caxambu; 11-Guinda; 12-Extração; 13-Campo da Croa; 14-Cuiabá; 15-Gouveia e 16-Vau

\begin{tabular}{|c|c|c|c|}
\hline \multirow{8}{*}{ 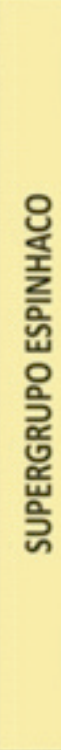 } & \multirow{5}{*}{ 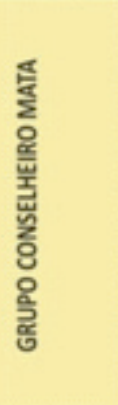 } & Fm. Rio Pardo Grande & $\begin{array}{l}\text { Filitos e metassiltitos com intercaloçbles quartziticas alèm de } \\
\text { lentes e niveis de mármores dolomiticos }\end{array}$ \\
\hline & & Fm. Córrego Pereira & $\begin{array}{l}\text { Quartzitos de granulometria média a grossa, micáceos ou } \\
\text { nø̄o, localmente feldspóticos, com niveis filiticos }\end{array}$ \\
\hline & & Fm. Córrego Bandeira & $\begin{array}{l}\text { Filitos e metassiltitos predominam sobre menores } \\
\text { quantidodes de quartzitos finos a médios }\end{array}$ \\
\hline & & Fm. Córrego dos Borges & $\begin{array}{l}\text { Quartzitos puros ou micdceos, eventualmente com corpos de } \\
\text { metabrechas e/ou metaconglomerados }\end{array}$ \\
\hline & & Fm. Santa Rita & $\begin{array}{l}\text { Filitos e metassiltitos com intercalaçoles quartziticas finas a } \\
\text { medias, mais espessas para o topo }\end{array}$ \\
\hline & \multicolumn{2}{|c|}{ Fm. Galho do Miguel } & Quartzitos finos cam megaestratificaçōes cruzadas \\
\hline & \multirow{2}{*}{ 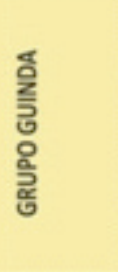 } & Fm. Sopa-Brumadinho & $\begin{array}{l}\text { Filitos e quartzitos finos micáceos (Mb. Datas), seguidos de } \\
\text { quartzitos ferruginosos ou näo com lentes, niveis e diques de } \\
\text { metoconglomerados polimíticos, filitos hematiticos ou näo } \\
\text { (Mb. Caldeiröes), filitos, quartzitos e metabrechas } \\
\text { diamantiferas (Mb. Campo Sampaio) }\end{array}$ \\
\hline & & Fm. SĨo Joฮ̄o da Chapada & $\begin{array}{l}\text { Quartzitos, metabrechas e metaconglomerados ("A"), filitos } \\
\text { hematiticos e xistos verdes ("B"), quartzitos fluviais cam } \\
\text { lentes de metaconglomerados e filitos }(" C) \text { ( })\end{array}$ \\
\hline \multirow{2}{*}{\multicolumn{2}{|c|}{ GRUPO COSTA SENA }} & Fm. Bandeirinha & $\begin{array}{l}\text { Quartzitos variados fluviais, marinhos e edlicos, com } \\
\text { intercalaçöes de lentes de metoconglomerados }\end{array}$ \\
\hline & & Fm. Barão do Guaicuí & $\begin{array}{l}\text { Xistos a quartzo e micas, com ou sem cianito, com quartzitos } \\
\text { e metavulcanitos }(2,1 \mathrm{Ga}) \text { intercalados }\end{array}$ \\
\hline \multicolumn{3}{|c|}{ GRUPO PEDRO PEREIRA } & $\begin{array}{l}\text { Metavuicanitos ultramáficos e móficos, seguidos de BIF's e } \\
\text { metavulcânicas ácidas }(2,95 \mathrm{Ga})\end{array}$ \\
\hline \multicolumn{3}{|c|}{ COMPLEXO DE GOUVEIA } & $\begin{array}{l}\text { Gnaisses, migmatitos e anfibolitos intrudidos por corpos } \\
\text { graniticos }(2,85 \mathrm{Ga}) \text { com megacristais de feldspato potássico }\end{array}$ \\
\hline
\end{tabular}

Figura 2: Quadro sinótico estratigráfico proposto por Knauer (1999) para os terrenos arqueanos, paleo-e mesoproterozóicos da região central da Serra do Espinhaço Meridional. 


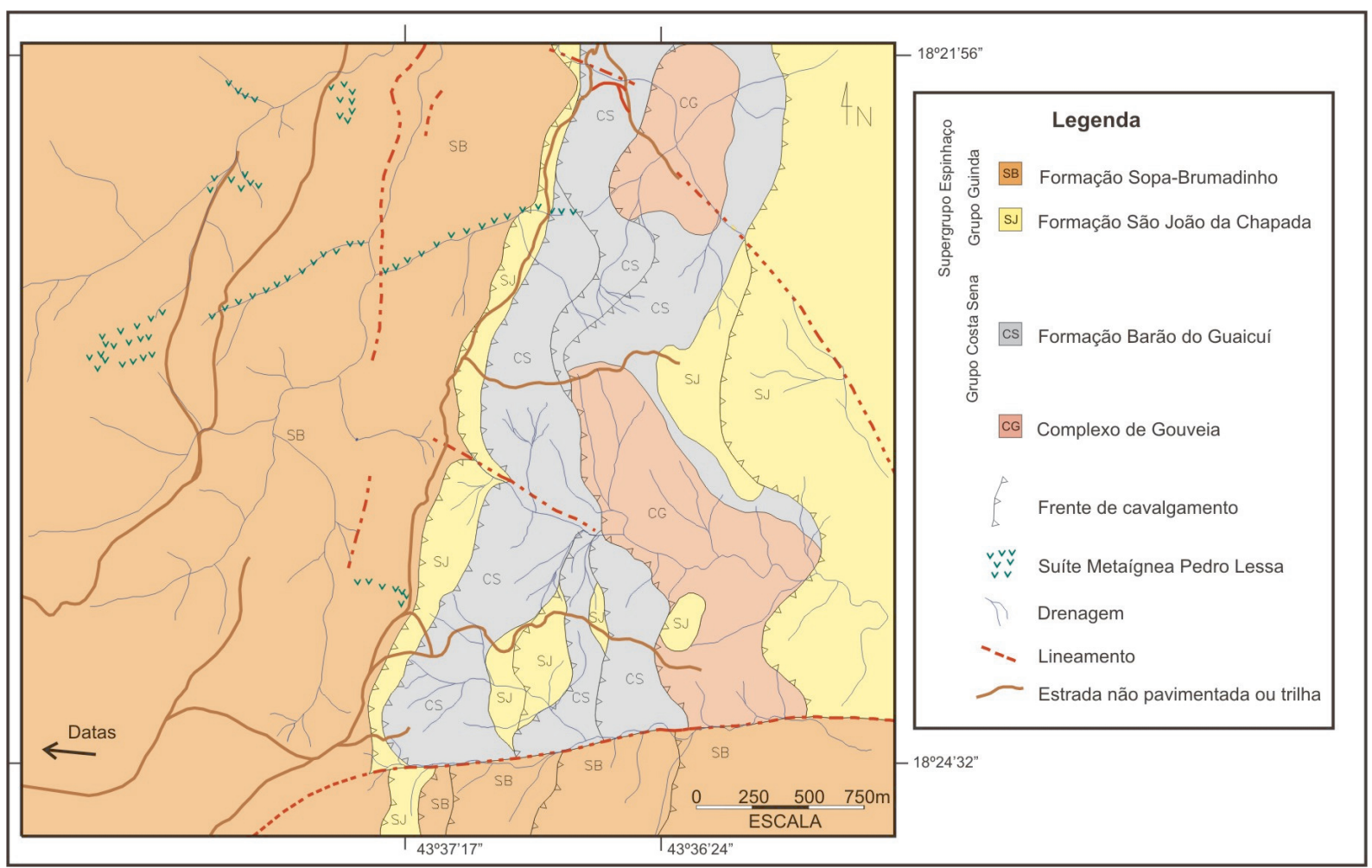

Figura 3: Mapa geológico simplificado da região da Serra da Matriculada, municipio de Datas (MG).

Sena é subdividido nas Formações Barão do Guaicuí (base) e Bandeirinha (topo), sendo que esta última unidade, constituída por quartzitos (micáceos, puros ou ferruginosos) de granulometria variando de fina a média, contendo intercalações de metaconglomerados polimíticos com matriz quartzítica, não aflora na região investigada. A Formação Barão do Guaicuí é constituída por quartzo-mica xisto, contendo muitas vezes cianita, turmalina e mais raramente lazulita, mostrando intercalações de quartzo xistos, quartzitos, sericita xistos, formações ferríferas bandadas, xistos verdes e metavulcanitos ácidos, estes últimos datados por Machado et al. (1989), através do método U-Pb em zircões, obtendo-se idades de $2049+3 /-2 \mathrm{Ma}$. Alguns trabalhos (e.g. Dossin et al. 1990; AlmeidaAbreu 1993) sugerem que a maior parte destas rochas corresponda a milonitos das rochas graníticas/ gnáissicas eventualmente derivadas de processos de extensão; outros autores (Fogaça 1982, 1985; Knauer 1990) defendem uma origem sedimentar para essa unidade.

O conjunto de metassedimentos essencialmente clásticos que compõem o Supergrupo Espinhaço foram divididos por Pflug (1968) em oito formações, sendo que as duas inferiores foram subdivididas e detalhadas por Schöll \& Fogaça (1979). Uma primeira reunião dessas unidades em dois grupos, Diamantina (formações São João da Chapada, Sopa-Brumadinho e Galho do Miguel) e Conselheiro Mata (formações Santa Rita, Córrego dos Borges, Córrego da Bandeira, Córrego Pereira e Rio Pardo Grande), é devida a Dossin et al. (1984).

Knauer (1990) sugere uma divisão em três conjuntos:
Grupo Guinda (em substituição ao Grupo Diamantina, reunindo as formações São João da Chapada e SopaBrumadinho), Formação Galho do Miguel e Grupo Conselheiro Mata. Por outro lado, Almeida-Abreu (1993) inclui no Grupo Guinda, além das formações São João da Chapada e Sopa-Brumadinho, as formações Bandeirinha, na base, e Galho do Miguel, no topo.

Proposta em Knauer (1990) a Suíte Metaígnea Pedro Lessa agrupa metagabros e metadiabásios na forma de diques e soleiras com idades de intrusão próximas aos $906 \pm 3$ milhões de anos (datação U/Pb em zircão e badelleyita, Machado et al. 1989), e posteriormente metamorfisadas no fácies xisto verde. Esses corpos são notavelmente expressivos nos metassedimentos do Supergrupo Espinhaço, com concentração destacada nas formações São João da Chapada, Sopa-Brumadinho e Galho do Miguel.

A estruturação do setor meridional da Serra do Espinhaço é atribuída a um sistema de frentes de cavalgamento/zonas de cisalhamento dúctil, cujos planos possuem direções norte-sul e mergulhos moderados até altos para os quadrantes leste. Estudos estruturais (e.g. Herrgesell 1984, Herrgesell \& Pflug 1986, Rolim 1992) mostram que pelo menos a maior parte destas frentes de cavalgamento/zonas de cisalhamento dúctil corresponde a rampas frontais formadas a partir de grande transporte de massa aproximadamente de leste para oeste.

Dentre as estruturas planares de origem tectônica, Knauer $(1990,1999)$ destaca uma foliação "Sn", mais facilmente reconhecida nos litotipos pelíticos, mas também eventualmente observável em quartzitos e metaconglomerados da unidade. Sua direção situa-se, 
normalmente, entre $\mathrm{N} 05^{\circ} \mathrm{W}$ e $\mathrm{N} 15^{\circ} \mathrm{E}$, com mergulhos moderados até altos para os quadrantes leste.

Nas áreas menos deformadas, duas estruturas planares se destacam: $\mathrm{S}_{\mathrm{n}+1}$ e $\mathrm{S}_{\mathrm{n}+2}$. A estrutura planar $\mathrm{S}_{\mathrm{n}+1}$ é representada por uma clivagem (de fratura ou ardosiana) com direções próximas a N-S e com altos mergulhos para leste, a qual evolui, localmente, para uma xistosidade. Knauer (1999) relaciona essa foliação às grandes dobras abertas (até localmente fechadas) com eixo N-S, características da maior parte das áreas de afloramento do Supergrupo Espinhaço.

A terceira estrutura planar $\left(\mathrm{S}_{\mathrm{n}+2}\right)$, com direção E-W e mergulhos sub-verticais, apresenta-se, também, como uma clivagem de fratura nas rochas mais competentes e de crenulação nos xistos e filitos, sendo caracterizada por uma ocorrência menos freqüente e conspícua do que $S_{n+1}$ (Rolim 1992).

A estrutura linear mais comum é representada por uma lineação de estiramento ou mineral (sericita/ moscovita, clorita, hematita e, localmente, cianita) com direções próximas a $\mathrm{S} 70^{\circ}-85^{\circ} \mathrm{E}$, também, freqüentemente marcada por estiramento de seixos de metaconglomerados (e.g. Schöll \& Fogaça 1981, Silva \& Uhlein 1985).

\section{METODOLOGIA}

Um grande número de técnicas de quantificação (e/ou análise) da deformação baseados em conceitos iniciais propostos por Ramsay (1967), Robin (1977); Sanderson (1977) e Fry (1979) têm sido propostos nas últimas décadas. Os métodos exigem a presença de "marcadores de deformação", cujas relações de forma, arranjo e posicionamento permitem quantificar as mudanças de um corpo rochoso quando sujeito à esforços tectônicos.

Muitos dos trabalhos apresentados nos últimos anos (e.g. Knauer 1999) consideram dois métodos clássicos: o método desenvolvido por Fry (1979) e suas variações, e o chamado Método $\mathrm{R}_{\mathrm{f}} / \varphi$ ' (Ramsay 1967, Ramsay \& Huber 1983, Lisle 1985).

O método desenvolvido por Fry (1979) e detalhadamente descrito por Fiori (1997) fornece uma rápida solução para a determinação da elipse de deformação, sendo facilmente aplicável a rochas ígneas equigranulares. Este método assume por princípio que as partículas consideradas têm distribuição uniforme antes dos eventos de deformação. Assim, as distâncias entre os centros, independentemente da direção considerada, seriam aproximadamente as mesmas, com a deformação tectônica sendo marcada por uma modificação nestas distâncias, com seu aumento no campo extensional e sua redução no campo contracional. Sua aplicação em metassedimentos mostrou-se factível, desde que consideradas as correções necessárias nos fatores deposicionais e diagenéticos que imprimem assimetrias nos pacotes (Knauer,1999).

O método $\mathrm{R}_{\mathrm{f}} / \varphi$ ' (discutido em Ramsay \& Huber 1983, Lisle 1985 e Simpson 1988) assume como princípio, que os objetos elipsoidais observados são deformados em conjunto (e na mesma proporção) com a matriz que os envolve. Para sua aplicação, são medidas as razões entre os eixos maior e menor de vários objetos $\left(R_{f}\right)$ e a sua orientação relativa $(\varphi$ '), as quais são dependentes não apenas do strain, mas também da sua orientação original $(\theta)$ e das razões axiais originais $\left(\mathrm{R}_{0}\right)$. Normalmente estes dois últimos parâmetros são desconhecidos, sendo determinados estatisticamente através da aplicação do método original ou de suas modificações posteriores.

\section{Os Parâmetros da Deformação}

As técnicas de quantificação $\mathrm{R}_{\mathrm{f}} / \varphi^{\prime}$ (representada pelo cálculo da média harmônica - $\mathrm{MH}$ - das razões de deformação de cada grão) e Fry aplicadas nas amostras coletadas na região da Serra da Matriculada permitem apenas análises bidimensionais, que tratadas em conjunto com observações diretas definem apenas alguns fatores: elipsidade, ou seja, razão entre o comprimento do eixo maior e menor da elipse de deformação, originada de um círculo unitário $(R s)$, ângulo entre o eixo maior da elipse de deformação e a direção da foliação $(\theta)$, grau de arredondamento dos grãos e flutuação $(\Delta)$, que corresponde à diferença entre as orientações extremas do eixo maior de cada seixo e uma linha horizontal de referência.

Os demais parâmetros necessários para a quantificação da deformação são obtidos através da associação destes dados com aqueles dos dois planos analisados (planos cinemáticos XZ e YZ). Uma discussão detalhada para a obtenção de parte destes parâmetros pode ser encontrada, entre outros, em Ramsay \& Huber (1983) e em Fiori (1997).

Um parâmetro facilmente obtido a partir dos dados das seções paralelas a XZ e YZ corresponde ao Parâmetro de Flinn, definido pela fórmula:

$$
\mathrm{k}=\left(\mathrm{R}_{\mathrm{xy}}-1\right) /\left(\mathrm{R}_{\mathrm{yz}}-1\right)
$$

$\mathrm{O}$ Parâmetro de Flinn (k) é empregado para a definição da forma do elipsóide de deformação. Desta forma, quando apresenta valores maiores que 0 e menores que 1 , define elipsóides oblatos, situados no campo do achatamento aparente, enquanto valores maiores que a unidade, definem elipsóides prolatos, que se originam no campo da constrição aparente. Valores iguais a 1 caracterizam uma deformação plana (plane strain).

O chamado Parâmetro de Lode (v) utiliza os valores logarítmicos do comprimento do semi-eixo do elipsóide de deformação para uma melhor descrição da forma deste elipsóide, enquanto que a quantidade da deformação cisalhante em plano octaedral pode ser definida pelo Parâmetro de Nadai $(\varepsilon)$. Estes dois parâmetros, onde:

$$
\begin{aligned}
& v=\left(\ln R_{y z}\right)-\left(\ln R_{x y}\right) /\left(\ln R_{y z}+\left(\ln R_{x y}\right) e\right. \\
& \varepsilon=(1 / \sqrt{3})\left[\left(\ln R_{x y}\right)^{2}+\left(\ln R_{y z}\right)^{2}+\left(\ln R_{x z}\right)^{2}\right]^{1 / 2}
\end{aligned}
$$
são tratados em conjunto no chamado "Diagrama de Hossack” (Hossack 1968 in Ramsay \& Huber 1983), 
que permite a definição das mudanças percentuais sofridas pelos eixos X, Y e Z durante a deformação.

\section{TRATAMENTO DAS AMOSTRAS}

As amostras de quartzitos utilizadas para a quantificação da deformação foram coletadas orientadas em campo, com posterior definição dos cortes a serem confeccionados: paralelos a lineação de estiramento mineral (plano XZ) e nos cortes a ela perpendiculares (plano YZ).

As lâminas obtidas foram descritas e fotografadas, permitindo a seleção daquelas mais apropriadas para a aplicação dos métodos $\mathrm{R}_{\mathrm{f}} / \varphi$ ' e Fry. Após esta seleção, os grãos de cada uma das seções foram cuidadosamente desenhados em overlay apropriado.

O overlay de cada seção foi "colorido" manualmente, separando desta forma matriz e grãos, sendo posteriormente tratados em programas gráficos (tais como "PaintShop Pro" versão 02, e "CorelDraw", versão 12) para a geração de imagens apropriadas.
Estas imagens foram exportadas para o programa "ImageTool", um analisador de imagens, o qual definiu objetos, sua orientação, seus tamanhos, relações axiais e grau de arredondamento, entre outros atributos. Os dados assim gerados foram transportados para o programa "Microsoft Excel" e para o programa $\mathrm{R}_{\mathrm{f}} / \varphi$ desenvolvido por Mulchrone \& Meere (2001), gerando planilhas e gráficos adequados para a aplicação do Método $\mathrm{R}_{\mathrm{f}} / \varphi$ ' e de todos os parâmetros dele decorrentes.

Para a obtenção dos dados através do método Fry e construção dos diagramas correspondentes foi utilizado o programa NewFry 1.2 (Tolson, 1996). As amostras utilizadas foram preparadas semelhantemente à técnica $\mathrm{R}_{\mathrm{f}} / \varphi$, com a diferença que em cada overlay foram determinados os centros dos grãos, definindo as concentrações de pontos necessárias para a interpretação através do método Fry. As informações obtidas foram então transportadas para planilhas MS Excel permitindo seu tratamento matemático e definição dos parâmetros X, Y, Z.

Tabela 1: Resultados obtidos com a aplicação de diferentes técnicas de quantificação da deformação em amostras de quartzitos da região da Serra da Matriculada, Datas (MG). Arred. corresponde ao grau de arredondamento das amostras.

\begin{tabular}{|c|c|c|c|c|c|c|c|c|}
\hline Amostra & Arred & $R f / p h i$ & $M H$ & Fry & Rs & RO & $\vartheta$ & $\Delta$ \\
\hline $84 y z$ & 0,33 & 5,16 & 4,38 & 2,39 & 5,26 & 1,92 & 59 & 16 \\
\hline $85 x z$ & 0,45 & 3,39 & 3,18 & 2,24 & 3,42 & 1,57 & 57 & 17 \\
\hline $85 y z$ & 0,76 & 1,83 & 1,76 & 1,94 & 1,87 & 1,31 & 58 & 24 \\
\hline $87 y z$ & 0,74 & 1,96 & 1,85 & 2,54 & 1,96 & 1,46 & 63 & 33 \\
\hline $88 x z$ & 0,42 & 3,79 & 3,50 & 1,79 & 3,85 & 1,78 & 60 & 20 \\
\hline $88 y z$ & 0,63 & 2,55 & 2,36 & 1,57 & 2,63 & 1,72 & 63 & 30 \\
\hline $89 x z$ & 0,34 & 4,71 & 4,39 & 2,00 & 4,44 & 1,72 & 58 & 16 \\
\hline $90 x z$ & 0,41 & 3,80 & 3,61 & 2,18 & 3,33 & 1,58 & 58 & 18 \\
\hline $91 x z$ & 0,49 & 3,18 & 2,92 & 1,58 & 2,93 & 1,69 & 61 & 25 \\
\hline $91 y z$ & 0,48 & 2,98 & 2,83 & 1,80 & 3,28 & 1,69 & 60 & 22 \\
\hline $92 \times z$ & 0,52 & 2,53 & 2,46 & 1,66 & 2,79 & 1,39 & 55 & 16 \\
\hline $93 x z$ & 0,40 & 4,07 & 3,74 & 3,23 & 4,16 & 1,82 & 59 & 19 \\
\hline $94 x z$ & 0,40 & 4,12 & 3,88 & 2,41 & 4,29 & 1,61 & 56 & 14 \\
\hline $102 x z$ & 0,38 & 4,34 & 4,04 & 2,55 & 4,01 & 1,80 & 59 & 19 \\
\hline $102 y z$ & 0,42 & 3,87 & 3,40 & 2,27 & 4,83 & 2,44 & 65 & 26 \\
\hline $103 x z$ & 0,43 & 3,52 & 3,21 & 2,29 & 3,99 & 1,90 & 61 & 22 \\
\hline $104 x z$ & 0,48 & 3,20 & 2,90 & 2,17 & 3,55 & 2,13 & 65 & 30 \\
\hline $108 x z$ & 0,52 & 2,78 & 2,58 & 1,86 & 2,94 & 1,56 & 58 & 21 \\
\hline $110 x z$ & 0,43 & 3,84 & 3,51 & 2,31 & 3,44 & 2,02 & 64 & 29 \\
\hline $114 x z$ & 0,61 & 2,49 & 2,40 & 1,94 & 2,45 & 1,42 & 57 & 20 \\
\hline $116 \mathrm{xz}$ & 0,49 & 3,08 & 2,95 & 1,71 & 3,08 & 1,57 & 58 & 20 \\
\hline $116 y z$ & 0,79 & 1,67 & 1,62 & 1,82 & 1,71 & 1,38 & 64 & 36 \\
\hline $117 x z$ & 0,76 & 1,75 & 1,67 & 1,64 & 1,66 & 1,55 & 76 & 59 \\
\hline $117 y z$ & 0,78 & 1,64 & 1,59 & 2,20 & 1,74 & 1,42 & 65 & 38 \\
\hline $120 x z$ & 0,76 & 1,86 & 1,77 & 2,07 & 2,03 & 1,64 & 68 & 42 \\
\hline $120 y z$ & 0,79 & 1,58 & 1,53 & 1,67 & 1,52 & 1,38 & 71 & 50 \\
\hline $121 x z$ & 0,55 & 2,70 & 2,54 & 1,83 & 2,86 & 1,54 & 58 & 21 \\
\hline $125 x z$ & 0,52 & 3,00 & 2,75 & 3,00 & 3,03 & 2,13 & 68 & 38 \\
\hline $125 \mathrm{yz}$ & 0,69 & 2,21 & 2,02 & 2,62 & 2,26 & 1,85 & 71 & 46 \\
\hline $127 x z$ & 0,79 & 1,68 & 1,62 & 2,09 & 1,79 & 1,36 & 61 & 30 \\
\hline $127 y z$ & 0,78 & 1,67 & 1,60 & 1,93 & 1,68 & 1,57 & 76 & 59 \\
\hline $129 x z$ & 0,75 & 1,89 & 1,83 & 2,00 & 2,061 & 1,436 & 60 & 27 \\
\hline $129 \mathrm{yz}$ & 0,79 & 1,72 & 1,65 & 2,23 & 1,837 & 1,355 & 69 & 45 \\
\hline $131 x z$ & 0,47 & 3,44 & 3,26 & 2,73 & 3,184 & 1,784 & 58 & 19 \\
\hline $132 x z$ & 0,72 & 2,00 & 1,91 & 2,06 & 2,377 & 1,542 & 64 & 33 \\
\hline $132 \mathrm{yz}$ & 0,76 & 1,71 & 1,66 & 2,29 & 1,699 & 1,303 & 63 & 33 \\
\hline
\end{tabular}




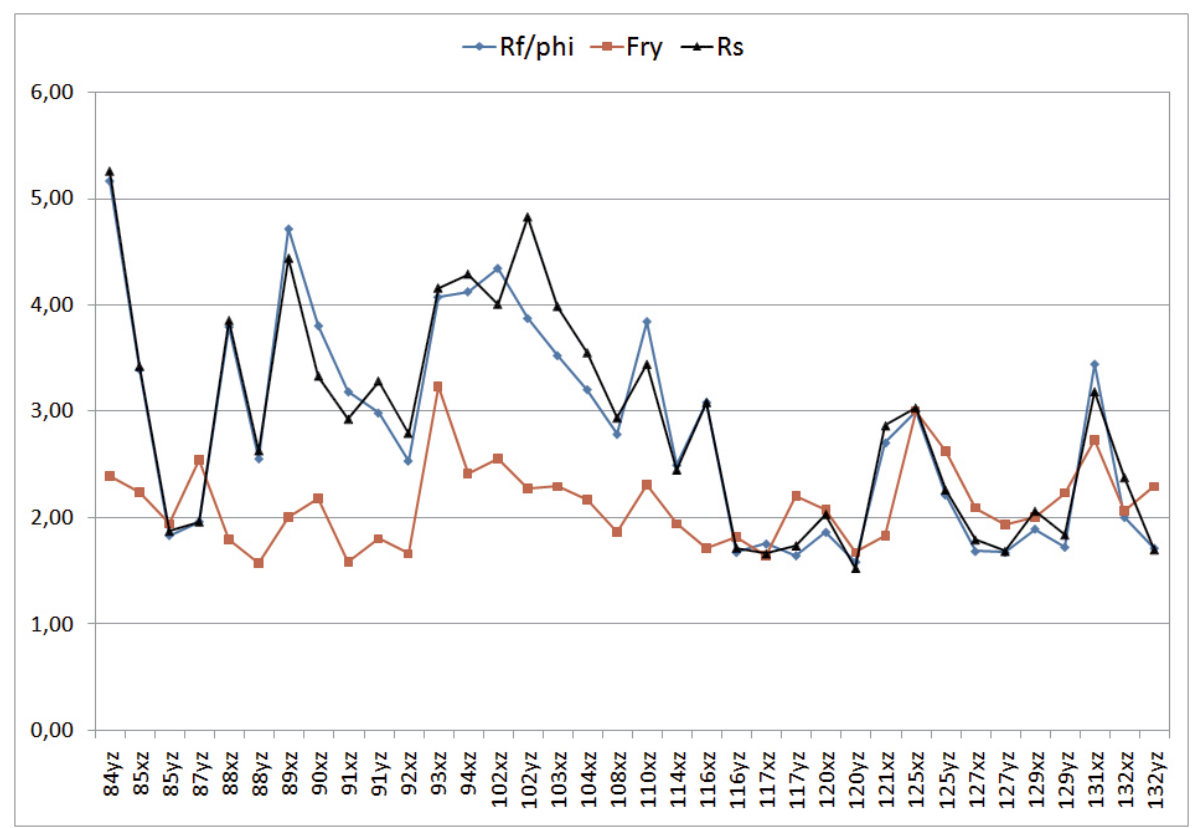

Figura 4: Comparação entre os resultados da razão de deformação obtidos através dos métodos $R / \varphi^{\prime}$, Fry e da fórmula $R s=(\text { Rmax*Rmin })^{1 / 2}$ desenvolvida por Ramsay (1967).

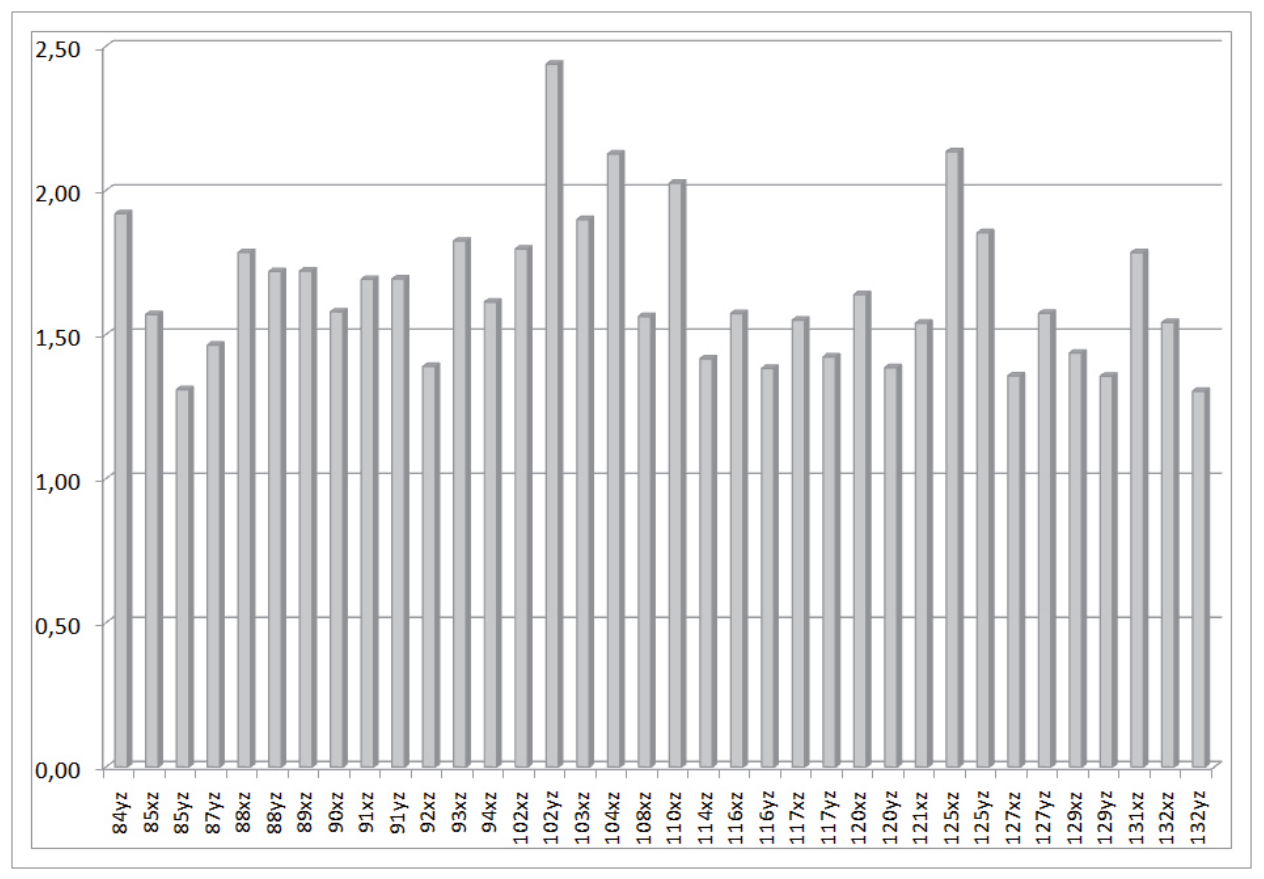

Figura 5: Valores obtidos para as razões iniciais $(R 0)$ dos grãos através da aplicação da fórmula $R_{0}=(R \max /$ Rmin) ${ }^{1 / 2}$ de Ramsay (1967).

\section{RESULTADOS E CONCLUSÕES}

A região de Datas, uma das mais intensamente deformadas da Folha Diamantina (Fogaça 1995), é caracterizada por um importante sistema de falhas inversas (correspondendo à "Zona de Falhamentos da Matriculada" de Schöll \& Fogaça 1981) que envolvem lascas tectônicas tanto de unidades do Supergrupo Espinhaço como do Grupo Costa Sena e do próprio Complexo de Gouveia.

Foram analisadas 25 amostras de quartzitos pertencentes às formações São João da Chapada ("Nível C") e Sopa-Brumadinho (Membro Caldeirões), de diferentes regiões da Serra da Matriculada, de tal modo que situações estruturais (tais como inversões estratigráficas e dobras centimétricas intraformacionais) e estratigráficas (porções com estruturas sedimentares ainda preservadas) estivessem representadas. Os valores da razão $R s$ obtidas para cada amostra nos métodos aplicados, do grau de arredondamento, do valor da flutuação $(\Delta)$ e do ângulo $\theta$ encontram-se sintetizados na Tabela 1 . 

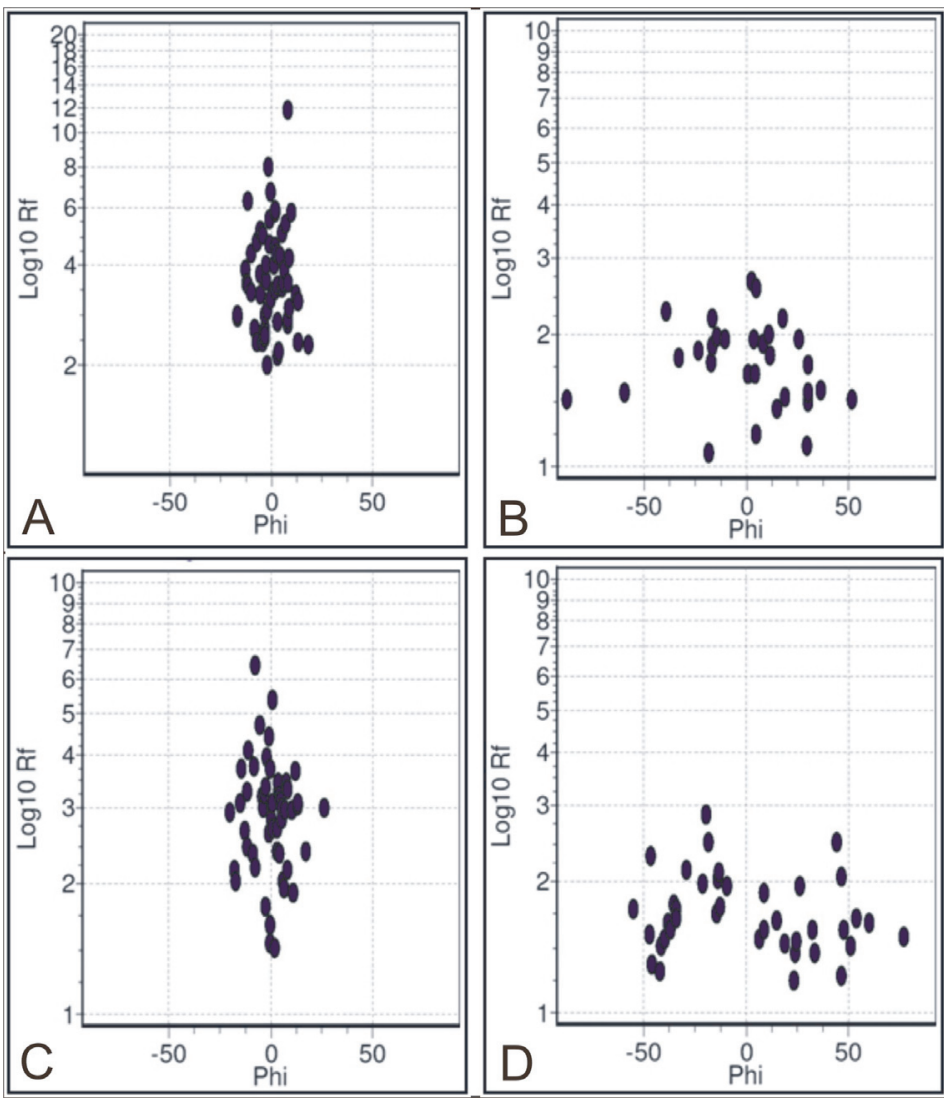

Figura 6: Gráficos $R / \varphi$ 'para as amostras (a) 102yz, (b) 117xz, (c) 125xz, (d) 129xz.

A análise dos dados indica, para a maioria das amostras, uma maior absorção da deformação pelos grãos em detrimento da matriz, cerca de $61 \%$ correspondendo a 22 seções, com valores de $R s$ variando, no plano $\mathrm{XZ}$, entre 1,68 e 4,71 quando determinados via cálculo da média harmônica dos valores fornecidos por $\mathrm{R}_{\mathrm{f}} / \varphi$ ' e entre 1,58 e 3,23 através do método Fry tradicional, valores estes podendo ser comparados na Figura 4.

Os valores da razão inicial $\left(\mathrm{R}_{0}\right)$, obtidos pela aplicação de $\mathrm{R}_{\mathrm{f}} / \varphi^{\prime}$, mostram-se relativamente altos em ambas seções, quando comparados com aqueles determinados por Paterson \& Yu (1994) para os processos sedimentares/diagenéticos $(1,31: 1,14: 1,00)$, variando entre 1,36 e 2,13 no plano e entre 1,30 e 2,44 em YZ (Figura 5).

Esses altos valores alcançados podem corresponder a problemas com a metodologia das técnicas aplicadas ou mesmo representar a atuação de evento tectônico anterior com orientação de esforços semelhante aquela do último tectonismo.

Já os valores da flutuação $(\Delta)$ determinados confirmam a impressão visual dos diagramas $R_{f} / \varphi$ ', sugerindo através dos ângulos baixos a moderados (observados para a ampla maioria das seções analisadas), uma alta deformação das amostras (Figura 6).

O Parâmetro de Flinn ("k" - Figura 7), considerando os dados obtidos através da aplicação dos métodos $\mathrm{R}_{\mathrm{f}} / \varphi$ e Fry, indica que praticamente todas as amostras consideradas representam elipsóides oblatos (exceções correspondem aos afloramentos JC-85 e JC-116, que através das análises via método $\mathrm{Rf} / \varphi$, apresentam posicionamento no campo do estiramento aparente, correspondendo, portanto, a elipsóides prolatos). Esse mesmo enquadramento é corroborado pela determinação do Parâmetro de Lode (Figura 8).

$\mathrm{O}$ ângulo $\theta$ (ângulo entre o eixo maior da elipse de deformação e a direção da foliação) quando plotado em um diagrama de rosetas mostra que $50 \%$ dos valores situam-se entre 60 e $70^{\circ}$ (Figura 9).

As estimativas das mudanças sofridas em cada eixo cinemático (considerando, novamente, os dados alcançados pelo método $R_{\mathrm{f}} / \varphi^{\prime}$ ) mostram variações entre $+17 \%$ e $+82 \%$ no eixo $X$, entre $-04 \%$ e $40 \%$ no eixo $\mathrm{Y}$, e entre $-53 \%$ e $-22 \%$ no eixo $\mathrm{Z}$.

Os resultados discutidos anteriormente situam-se dentro das expectativas iniciais com relação à maior parte das amostras. De um modo geral, praticamente todas as amostras coletadas nas proximidades de zonas de cisalhamento dúctil/frentes de cavalgamento (sejam elas observadas ou apenas inferidas) mostram valores de strain mais altos quando comparado aos dados existentes para a Serra do Espinhaço Meridional (Cordeiro, 2008; Knauer, 1999; Silva e \& Ulhein, 1985) compatíveis com o contexto geológico definido.

A maioria das amostras analisadas indica uma maior absorção da deformação pelos grãos, com valores de $R s$ variando, no plano $\mathrm{XZ}$, entre 1,78 e 4,71 quando estimados pela técnica $R_{\mathrm{f}} / \varphi^{\prime}$. Os dados obtidos também sugerem que o controle da deformação, 


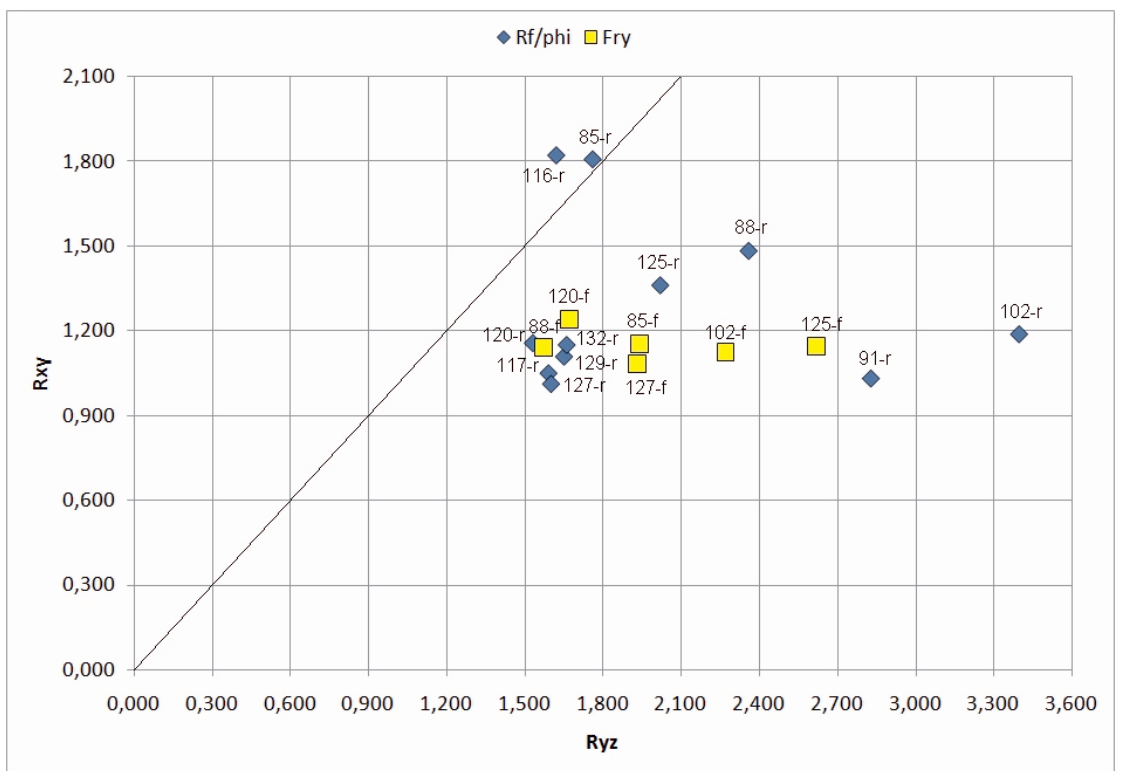

Figura 7: Diagrama de Flinn para as amostras da região da Serra da Matriculada, com aquelas seguidas por - $r$ designando determinações de Rs através do cálculo da média harmônica dos grãos e aquelas seguidas por - correspondendo a determinações via método Fry.

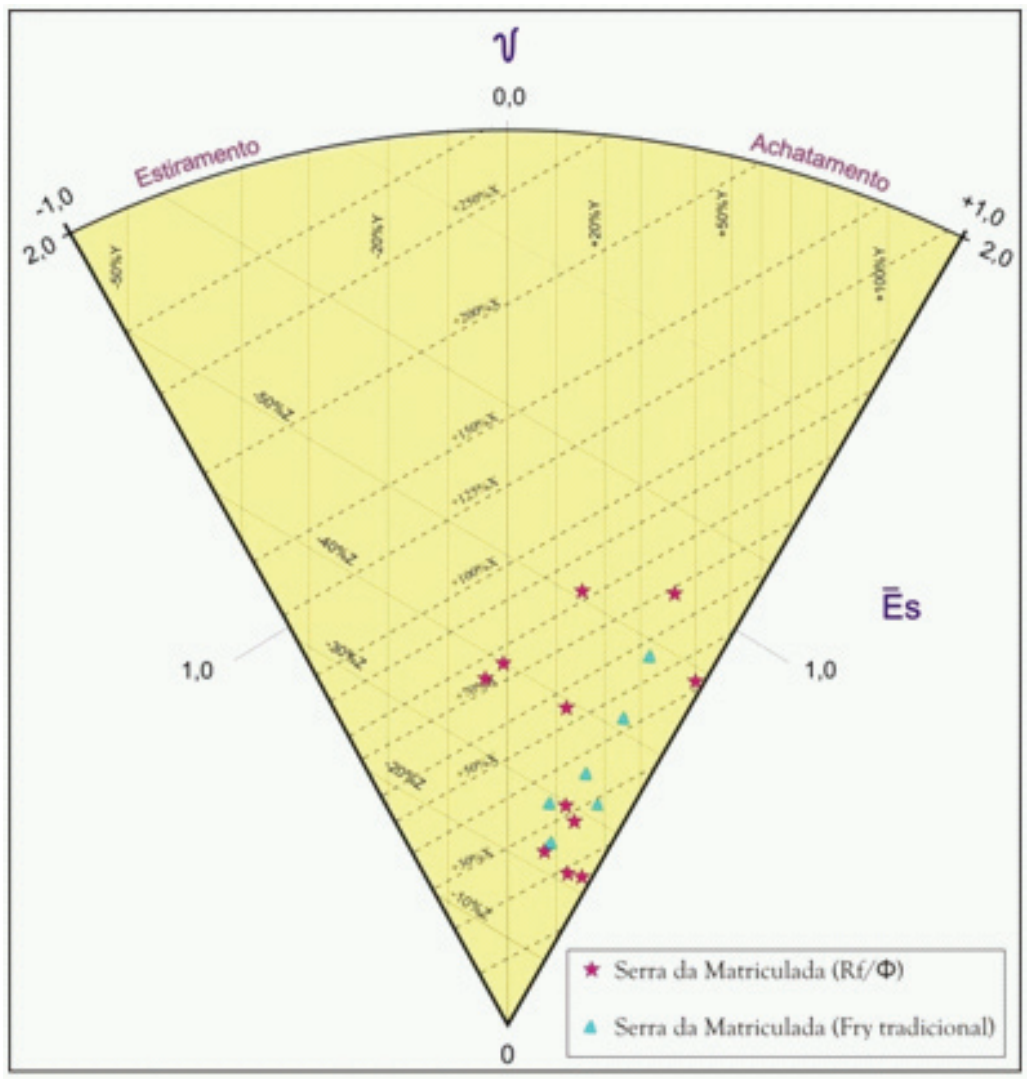

Figura 8: Diagrama de Hossack para as amostras coletadas na região da Serra da Matriculada mostrando as estimativas de mudanças em cada eixo cinemático. As estrelas indicam o posicionamento através da técnica de quantificação $R / \varphi^{\prime}$, já os triângulos apontam o posicionamento das mesmas amostras via método Fry.

mais do estratigráfico é litológico, sendo esta maior nos litotipos mais micáceos. Além disso, pode-se visualizar através das elipses de deformação plotados na Figura 10 (principalmente quando considerados os valores obtidos por $\mathrm{R}_{\mathrm{f}} / \varphi$ '), valores maiores de deformação próximos à zona de contato entre as formações São João da Chapada ("Nível C") e
Sopa-Brumadinho (Membro Caldeirões) e um aumento relativo para oeste deste contato, sugerindo uma maior deformação interna nos metassedimentos da Formação Sopa-Brumadinho, seja pela existência de litotipos mais micáceos ou mesmo pela presença, local e relativamente comum, de dobras de pequeno/médio porte por toda a unidade. 


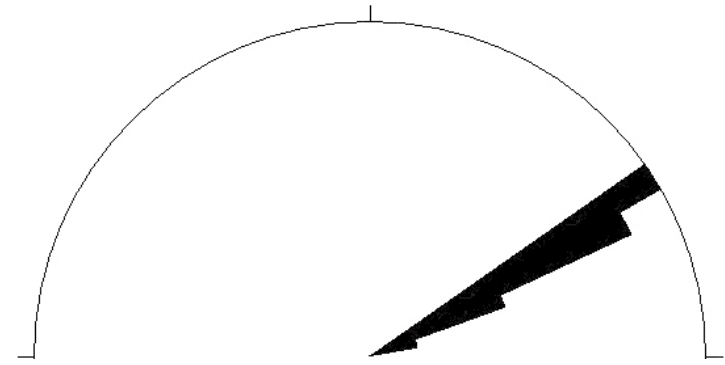

Figura 9: Diagrama de rosetas para as medidas do ângulo $\theta$ calculado para as amostras analisadas na região da Serra da Matricula. A pétala mais larga (60-70 ) corresponde a 50\% das medidas.

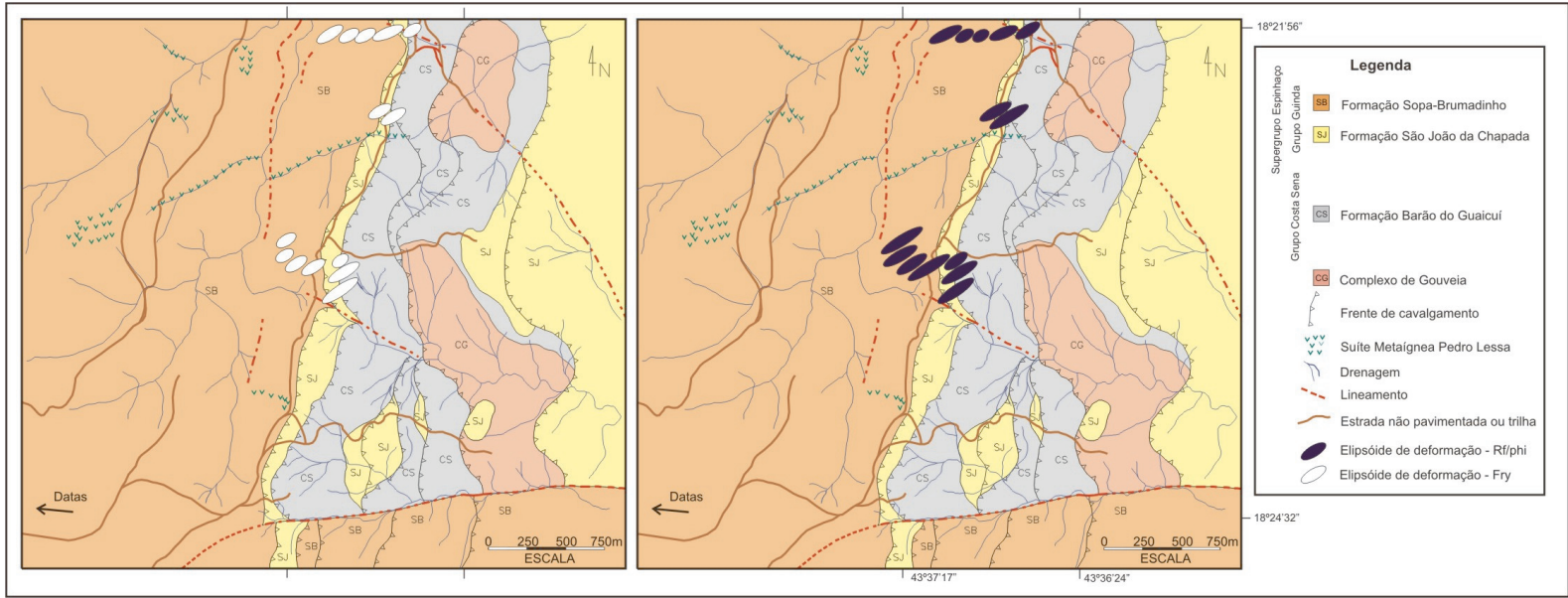

Figura 10: Distribuição das elipses de deformação das amostras analisadas na região da Serra da Matriculada, elipses em branco correspondem aos resultados obtidos via aplicação da técnica Fry e em azul aos resultados fornecidos pelo método $R / \varphi$ '.

\section{AGRADECIMENTOS}

Os autores expressam seus agradecimentos aos professores J. J. G. Quéméneur e C.A. Rosiére, à Claydson Faria, à Tárik Cordeiro, aos alunos de diversas universidades brasileiras que estagiaram no Centro de Geologia Eschwege e aos revisores pelas contribuições. J. Cordeiro agradece também ao CNPq pela bolsa concedida.

\section{REFERÊNCIAS BIBLIOGRÁFICAS}

Almeida-Abreu P.A. 1993. A evolução geodinâmica da Serra do Espinhaço Meridional, Minas Gerais, Brasil. Tese Dout., Univ. Freiburg, $150 \mathrm{pp}$.

Dossin I.A., Uhlein A., Dossin T.M. 1984. Geologia da Faixa Móvel Espinhaço em sua porção meridional, MG. In: Anais do XXXIII Cong. Bras. Geol., Anais 7: 3118-3134, Rio de Janeiro.

Dossin I.A., Dossin T.M., Chaves M.L.S.C. 1990. Compartimentação estratigráfica do Supergrupo Espinhaço em Minas Gerais - Os grupos Diamantina e Conselheiro Mata. Rev. Bras. Geocienc., 20 (1-4), 178-186.

Dossin I.A., Chaves M.L.S.C., Uhlein A., Alvarenga C.J.S. 1985. Geologia e depósitos diamantíferos da região de Sopa, Diamantina, Minas Gerais. In: III Simp. Geol. Minas Gerais, Anais, pp. 276-290, B. Horizonte.

Fiori A.P. 1997. Introdução à análise da deformação. Ed. UFPr, 249 pp., Curitiba.

Fogaça A.C.C. 1982. Geologia e mineralizações auríferas da região de Costa Sena (Minas Gerais). UnB, Rel. Int., 28 pp. Brasília.
Fogaça A.C.C. 1985. Serra do Espinhaço Meridional: geologia dos terrenos arqueanos e proterozóicos. III Simp. Geol. Minas Gerais, Anais, pp. 377-383, Belo Horizonte.

Fogaça A.C.C. 1995. Geologia da Folha Diamantina. Projeto Espinhaço, Convênio COMIG-UFMG, 98 pp., Belo Horizonte.

Fogaça A.C.C., Almeida Abreu P.A., Schorscher H.D. 1984 Estratigrafia da seqüência supracrustal arqueana da porção mediana-central da Serra do Espinhaço Meridional, Minas Gerais. In: Anais do XXXIII Cong. Br. Geol., Anais 6: 26542667, Rio de Janeiro.

Fry N. 1979. Random point distributions and strains measurements in rocks. Tectonoph. 60: 89-105.

Herrgesell G. 1984. Das Prakambriun am Ostrand der nordlichen Serra do Cipó (Serra do Espinhaço, Minas Gerais, Brasilien). Un. Freiburg, Tese Dout., 247 pp., Freiburg.

Herrgesell G. \& Pflug R. 1986 The thrust belt of the southern Serra do Espinhaço, Minas Gerais, Brazil. Zbl. Geol. Palaontol., Teil I, 9/10: 1405-1414, Stuttgart.

Kalt H. 1991. Untersuchungen zur Schertektonik in der südlichen Serra do Espinhaço und im angrenzenden Teil des São Francisco Beckens, Minas Gerais, Brazilien. Tese Dout., Univ. Freiburg/ Alemanha, 118p.

Knauer L.G. 1990. Evolução geológica do Precambriano da porção centro-leste da Serra do Espinhaço Meridional e metalogênese associada. Diss. Mestrado, UNICAMP, 298p.

Knauer L.G. 1999. Aspectos estratigráficos e estruturais das unidades proterozóicas da Serra do espinhaço meridional e suas implicações para a caracterização do Evento Uruaçuano. Tese Dout., UNESP 226pp., Rio Claro. 
Lisle R.J. 1985. Geological strain analysis. Pergamon Press, 76 pp. Lisle R.J. 1994. Palaeostrain analysis. In: Continental Tectonics, pp. 29-42.

Machado N.; Schrank A.; Abreu F.R.; Knauer L.G.; Almeida Abreu, P.A. 1989. Resultados preliminares da geocronologia $\mathrm{U} / \mathrm{Pb}$ na Serra do Espinhaço Meridional. In: V Simp. Geol. Minas Gerais, Anais, pp. 171-174, Belo Horizonte.

Mulchrone K.F. \& Meere P.A. 2001. A windows program for analysis of tectonic strain using deformed elliptical markers. Computers \& Geosciences. 27: 1251-1255.

Paterson S.R. \& Yu H. 1994. Primary fabric ellipsoids in sandstones: implication for depositional processes and strain analysis. J. Struct. Geol. 16: 505-518.

Pflug R. 1965. A geologia da parte meridional da Serra do Espinhaço e zonas adjacentes, Minas Gerais. DNPM/DGM, Bol. 226: 1-51, Rio de Janeiro.

Pflug R. 1968. Observações sobre a estratigrafia da Série Minas na região de Diamantina, Minas Gerais. DNPM/DGM, Not. Prel. Est. 142: 1-20, Rio de Janeiro.

Ragan D.M. 1985. Structural Geology: An introduction to geometrical techniques. John Wiley \& Sons, Inc., 393 pp.

Ramsay J.G. 1967. Folding and fracturing rocks. McGraw Hill Book Co., 327 pp, N. York.

Ramsay J.G. \& Huber M.I. 1983. The techniques of modern structural geology: strain analysis. Acad. Press, 278 pp, N. York.
Robin P.Y.F. 1977. Determination of geologic strain using randomly oriented strain markers of any shape. Tectonoph., 42: T7-T16.

Rodrigues S.W.de O. \& Faleiros, F.M. 2007. Avaliação de métodos de quantificação da deformação finita por meio de simulações computacionais de deformação progressiva. Rev. Bras. Geoc., 37 (3): 504-514.

Rolim V.K. 1992. Uma interpretação das estruturas tectônicas do Supergrupo Espinhaço baseada na geometria dos falhamentos de empurrão. Rev. Esc. Minas, 45(1 e 2): 75-77. Ouro Preto.

Sanderson D.J. 1977. The analysis of finite strain using lines with an initial random orientation. Tectonoph, 43: 199-211.

Scholl W.U. \& Fogaça A.C.C. 1979. Estratigrafia da Serra do Espinhaço na região de Diamantina. In: I Simp. Geol. Minas Gerais, Anais, pp. 55-73, Diamantina.

Scholl W.U. \& Fogaça A.C.C. 1981. Geologia das quadrículas Guinda e Gouveia. DNPM/CPRM/CGE, Rel. Int., 63 pp., Diamantina.

Silva M.E. \& Uhlein A. 1985. Analise da deformação finita nos metaconglomerados de Datas e Guinda, MG. In: II Simp. Geol. Minas Gerais, Anais, pp 125-138, B. Horizonte.

Silva R.R. 1995. Sequence stratigraphy and depositional systems of the lower Espinhaço in the region between Diamantina and Gouveia, Minas Gerais, Brazil. Tese Dout., Univ. Freiburg, Alemanha.

Simpson C. 1988. Strain analysis. In "Basic Methods of structural geology" (ed. S.Marshak \& G.Mitra), Prentice Hall.

Tolson G. 1996. Using a weighted density function to fit an ellipse to the Fry plot. (resumen). Geological Society of America Abstracts with programs, A71. 